Acompanhando aprendizagens amorosas na interface da metodologia de projetos de aprendizageme tecnologias digitais: um estudo de caso

Luciane Magalhães Corte Real Cleci Maraschin Margarete Axt

\title{
Following the love learnings
}

in the interface of learning projects methodology and digital technologies: 
Resumo: Este artigo analisa o percurso de um estudante do nível fundamental de uma escola pública em uma experiência de intervenção construída na interface da metodologia de Projetos de Aprendizagem e Tecnologias Digitais. Busca-se identificar as aprendizagens amorosas que emergiram na interação deste estudante na experiência proposta. O constructo 'Aprendizagem Amorosa' foi articulado a partir da confluência do referencial teórico da Biologia do Conhecer de Humberto Maturana e da Epistemologia Genética Jean Piaget. Os Projetos de Aprendizagem (PAs) e a interação dos alunos com as Tecnologias Digitais são a matriz da construção da rede de conversações da experiência vivida e analisada no estudo. As conclusões apontam para a importância da constituição de um domínio cooperativo para que exista a aceitação da legitimidade do outro que se operacionaliza na possibilidade de descentração cognitiva e afetiva. A existência de um domínio de ações de cooperação, está implicada com um emocionar que considera a legitimidade do outro na ação em jogo, logo, Aprendizagens Amorosas.

Palavras-chave: Aprendizagem Amorosa. Projetos de Aprendizagem. Tecnologias Digitais.

Abstract: This paper is related to an educational experience of intervention carried out in a public school maintained by the Cityhall of Porto Alegre city. The educational experience was based on the learning projects methodology along with the technological resources use. As for the theorethical background this article counts on the Genetic Epistemology of Jean Piaget and the Biology of Knowing proposed by Humberto Maturana. The results show the importance of the implied action emotions play in this net of conversations for the constitution of a cooperative group work, making the living together and intimacy a dominium of acceptance of the other legitimacy, which takes place through a cognitive and affective descentralization process. The learning projects methodology has offered several group interactions and exchanges, and the technological resources seem to have favored a big range of interaction among students by synchronous and asyncronous communication exchange.

Key-words: Computer in Education. Learning Projects. Intimacy and Living Together Transformation.

REAL, Luciane Magalhães Corte; MARASCHIN, Cleci; AXT, Margarete. Acompanhando aprendizagens amorosas na interface da metodologia de projetos de aprendizagem e tecnologias digitais: um estudo de caso. Informática na Educação: teoria \& prática, Porto Alegre, v.10, n.1, p.57-73, jan.jun. 2007. 


\section{Apresentação}

As práticas tradicionais de conviver, trabalhar, educar e, mesmo, de pensar e de conhecer têm sofrido transformações com o advento das novas tecnologias da comunicação. Instituições sociais, dentre elas a escola, recebem, quotidianamente, o impacto de um bombardeio de informações provindas de diferentes meios.

As novas ferramentas informáticas tornam-se cada vez mais presentes nos fazeres pedagógicos. Elas são introduzidas e utilizadas nas escolas de diferentes maneiras, podendo questionar ou não práticas pedagógicas baseada fortemente na transmissão de informações, que fomentam um modo de aprender calcado na memoração de conteúdos.

Em uma análise da produção na América do Norte e do Sul sobre a inserção de ferramentas tecnológicas na formação de professores para introdução da Internet nas escolas e sua utilização para cursos a distância Nevado et al (2002) identificam alguns problemas. Para os autores tornou-se evidente que, apesar das disposições à inovação, a falta de pesquisa sobre as potencialidades dessas ferramentas têm favorecido pseudo-inovações, reduzindo, as novas possibilidades abertas pelo uso das tecnologias, à simples otimizações das práticas tradicionais. Neste sentido, os autores consideram premente a necessidade de produção de conhecimento, mediante estudos que possibilitem diferenciar as condições para a transformação do processo educativo, enfatizando também a pesquisa sobre formação de professores utilizando ambientes telemáticos.

Concordando com os autores acima, pensamos que a Informática tem um grande potencial para transformar práticas pedagógicas baseadas na transmissão de conteúdos. Nessa direção é necessário produzir investigações so- bre experiências concretas que, ao avaliar os resultados, dêem suporte para essa introdução da informática nas escolas.

Com essa perspectiva existem alguns exemplos de pesquisas que têm investigado ambientes de aprendizagem (BOFF e GIRAFFA, 2002; FUKS, GEROSA, RAPOSO e LUCENA, 2004), ambientes colaborativos (FUKS, 2004), arquitetura de ambientes (SENO e VIEIRA, 2002), softawares educacionais (RUTHSCHILLING, 1999; CRISÓSTOMO, FREIRE, SILVA e MACEDO, 2002; GLADCHEFF, 2002), interações em ferramentas de comunicação textual (PIMENTEL e SAMPAIO, 2002), interatividade em ambientes a distância (PRIMO e CASSOL, 1999). Há também pesquisas que investigam questões pedagógicas no uso da informática na educação (FAGUNDES e NITZKE, 1999; ESTRÁZULAS, 1999; BASSO, FAGUNDES, TAROUCO e COSTA, 1999; AZEVEDO et all, 2004; VALENTINI, GRINGS, FAGUNDES e TAROUCO, 1999).

Uma linha de pesquisa têm analisado interações à distância tomando como foco de estudo as noções de auto-narrativa. Além dos mencionados, outros estudos têm utilizado, de maneiras diferentes, as tecnologias digitais a fim de investigar as redes de conversações presentes na interação dos participantes, como nos cita Eidelwein, (2001); Maçada, (2001); Mazzochi, (2001). Nesse sentido Teixeira (2005) sustenta que a interação com as tecnologias podem produzir deslocamentos nas redes de conversação em direção a invenção de novas coordenações de ações, podendo facilitar interações de reconhecimento e convivência com modos de viver e pensar distintos dos tomados como próprios, ampliando a possibilidade de produção de deslocamentos dos pontos de vista dos participantes. 
Com o intuito de estudar os deslocamentos que ocorrem nas redes de conversação tendo em vista processos de reconhecimento das diferenças e trabalho cooperativo delineamos uma experiência em uma escola. Propomos realizar uma interação entre estudantes, professores e pesquisadores utilizando como metodologia os Projetos de Aprendizagem acoplados às Tecnologias Digitais. O objetivo foi flagrar a aprendizagem amorosa que emergiu nas redes de conversações situadas a partir das emoções presentes no conversar dos participantes no ambiente construído a partir do percurso de um dos estudantes envolvidos.

\section{Aprendizagem amorosa}

Aprendizagem amorosa consiste em um construto pensado/construído na confluência da Biologia do Conhecer de Humberto Maturana e da Epistemologia Genética de Jean Piaget.

Para Maturana "As teorias que correntemente usamos para falar de aprendizagem, de conhecimento ou de saber, levam-nos a supor que aprender é a captação de algo independente de nós" (1992, p. 228). Esse autor refere que o conhecimento tem sido enfatizado, desde o renascimento como representação fiel de uma realidade independente do conhecedor. Com algumas exceções, a idéia que o mundo é prédado à experiência humana é predominante. Segundo essas teorias, o cérebro recebe informações proveniente dos órgãos sensoriais que são processadas na forma de representações mentais. Já, para a Biologia do Conhecer, não existe captação externa independente do observador. Um determinado mundo emerge a partir das coordenações de ações que estabelecemos em específicos domínios de conhecimento. Estamos sempre implicados na aprendizagem, no conhecimento e no mundo que construímos coletivamente. Nesse sentido, Maturana (1993) situa-se diferentemente de outros teóricos que consideram a aprendizagem como representação fiel da realidade. Piaget (1971) compartilha da idéia de que o conhecimento não consiste em uma cópia fiel dos objetos, sendo as imagens mentais produzidas por um longo processo de coordenações das ações de jogo e de imitação.

Maturana (2002) assinala que não há objetividade independente do observador que está sempre inserido em uma comunidade de observadores, ou seja, o observador não é um indivíduo mas uma posição de sujeito. A objetividade implica a consensualidade em termos dos critérios de validade existente entre os observadores que participam do mesmo domínio de conhecimento. Os efeitos de uma experiência assumem caráter objetivo quando dão origem a explicações dadas por um observador aceitas pela comunidade que participa. Ou seja, existe na objetivação do mundo um caráter subjetivo. Nesse sentido, Maturana (1999, p. 265) aponta que: "[...] a realidade que vivemos depende do caminho explicativo que adotamos, e este depende do domínio emocional no qual nos encontramos no momento da explicação". Esse autor refere que há dois caminhos explicativos. Quando o observador não se pergunta pela origem de suas habilidades cognitivas e as aceita como propriedades constitutivas suas, ele atua como se o que ele distingue preexistisse a sua distinção. Na suposição implícita de poder fazer referência a essa existência para validar seu explicar, Maturana refere-se à objetividade-semparênteses. A objetividade-entre-parênteses é a visão na qual não há uma objetividade independente do observador para validar o explicar. O observador está imerso na explicação. Na objetividade-sem-parênteses, toda verdade objetiva é universal, ou seja, válida para qualquer observador, porque é independente do que ele faz, a verdade se prova com uma correspondên- 
cia a essa realidade dada. No caminho explicativo da objetividade-entre-parênteses, não há verdade absoluta nem verdade relativa, mas muitas verdades diferentes em muitos domínios distintos de conhecimento. Estes dois caminhos explicativos não somente condicionam uma posição lógica, como apontado acima, mas delimitam tipos de relações emocionais diferentes. No caminho explicativo da objetividade-entre-parênteses, não se cria uma dinâmica de negação na convivência, uma vez que existem tantos mundos possíveis como possibilidades de relações consensuais recorrentes constitutivas dos distintos domínios de conhecimento. A emoção do amor é a que se vincula a possibilidade de um caminho explicativo da objetividade-entre-parênteses.

O amor, na Biologia do Conhecer (MATURANA; ZÖLLER, 2004), é definido como um modo de conviver no qual existe a experiência da aceitação do outro como legítimo outro na convivência. Essa emoção abre um campo de possibilidades de ação entre elas a confiança, a escuta, o respeito e a cooperação. Esse emocionar abre também uma posição frente ao conhecer, que Maturana define, como já explicitado, um caminho explicativo da objetividade-entreparênteses. Nessa perspectiva, a aprendizagem amorosa, ou seja, uma estrutura de convivência na qual a aceitação do outro seja legítima só emerge no caminho explicativo da objetividade entre-parênteses. Assim, ao falarmos de amor, não estamos referindo um sentimento individual, mas sim a um modo de relação no qual o outro (nesse artigo utilizamos outro em itálico para diferenciar do sentido de diverso ou de mais um) é tomado como legitimo outro. Trata-e de uma convivência que se produz por meio de uma ética da aceitação da diferença. Não uma tolerância, não um "apesar da" diferença. Mas um modo de conviver, existir e conhecer em um caminho explicativo-entre-parênteses.
Segundo Maturana et all (2004) a emoção do amor poderia ser a base explicativa da própria origem da linhagem humana. Para ele, o amor pode ser definido como uma emoção fundamental que podemos detectar em praticamente todos seres vivos (em especial nos mamíferos e nos humanos) e no devir de suas relações. Sempre que observamos uma conduta que leva ao encontro do outro, como legítimo outro, em coexistência com os demais, estamos falando de amor. Maturana (2002) relaciona as enfermidades com a falta de amor. Refere e exemplifica que o amor é encontrado até no acoplamento de uma semente com a terra quando há aceitação mútua. A congruência entre um grão começando a germinar, alimentado pelos nutrientes necessários que possibilitarão seu crescimento é a expressão de uma confiança implícita. Este tipo de confiança é que fundamenta a existência de todos os seres e é defraudada permanentemente. Podemos também observar no nascimento de um bebê a necessidade de amor, ou seja, ser aceito pelas pessoas que o cuidam. Maturana (2002, p. 72) refere a ética como a preocupação com as conseqüências de nossas ações sobre os outros, portanto pertencente ao domínio do amor e não ao domínio racional (no sentido de emoções amorosas e não de explicações racionais). O autor exemplifica que a Declaração dos Direitos Humanos e os discursos racionais sobre os direitos humanos só convencem os que já estão convencidos, pois o "racional é um operar num âmbito de coerências operacionais e discursivas baseado num conjunto de premissas fundamentais, aceitas a priori, que o determinam" (idem, p.72). Só o racional não garante a aceitação do outro como legítimo.

A Epistemologia Genética piagetiana apesar de não referir a noção de amor oferece alguns conceitos que podem ajudar a aprofundar as condições de possibilidade da emergência 
dessa estrutura de convivência e, mais do que isso, explicitar como os sujeitos podem se apropriar dessa noção. Uma das condições de possibilidade para que se dê a aceitação do outro éa descentração cognitiva. Existe um egocentrismo cognitivo mas também afetivo quando se toma o pressuposto explicativo de uma realidade sem parênteses. É o processo de descentração que possibilita colocar-se e mesmo entender o ponto de vista de outrem. Só que esse processo necessita também de uma estrutura de convivência diferenciada, e assim, fechamos um certo circuito, onde causas e consequências se realimentam.

Piaget (1973b) refere que no plano social a cooperação pode conduzir à prática solidária e à idéia de justiça, portanto a construção de valores. No plano intelectual a cooperação está intimamente ligada a descentração e abre possibilidades, ao liberar o sujeito de uma atitude egocêntrica, ao acesso ao domínio lógico. A cooperação é, por outro lado, no nível das relações interindividuais, o equivalente da reciprocidade lógica (p.123). Em uma perspectiva processual, a cooperação, marca uma passagem a equilíbrios cognitivos, definidos pelas relações entre os elementos de uma totalidade e a construção de normas por um ajustamento das interações.

Descentrar-se, ou seja, deslocar de seu centro e comparar uma ação com outras possíveis, particularmente, com as ações de outras pessoas, conduz a verdadeiras operações (idem, p.137). Em nossa investigação, acreditamos que essa condição implica em uma mudança estrutural que se dá na convivência, ou seja, descentrar-se é um modo de aprender a coordenar ações de forma diversa da que estava sendo processada.

Para Piaget a interação social, como a interação com objetos físicos, promove a cons- trução de um conjunto de relações que auxiliam a relativização e a capacidade de situar-se a si próprio entre essas relações graças a uma atividade de coordenação implicando a descentração e a reciprocidade de pontos de vista (PIAGET, 1973b).

A princípio, a atividade cognitiva está submetida à ação própria e ao ponto de vista imediato. Posteriormente, ela se libera, de forma progressiva, de seus limites iniciais, graças à descentração, processo fundamental do desenvolvimento cognitivo. Essa noção é definida por oposição à de centração (MONTAGERO e NAVILLE, 1998).

Se a descentração é o modo como se produz a saída do egocentrismo inicial, é portanto um processo de deslocamento emocional. Ao permitir a passagem de uma subjetividade autocentrada a uma objetividade entre-parênteses, institui um modo de explicação que considera a perspectiva do observador. A inserção de um ponto de vista próprio (posição de observador) em um conjunto de pontos de vista possíveis e a inserção do eu em um universo do qual ele não é mais o centro implica considerar a legitimidade do outro. Portanto podemos pensar que a descentração é uma condição de possibilidade emergência do amor.

Descentrar remete à capacidade de se desprender de um aspecto delimitado e considerado até então com exclusividade para se levar em consideração outros aspectos e finalmente coordená-los. Para Piaget (1977) a cada novo patamar, assiste-se a contínuas reorganizações a partir de elementos ou relações inicialmente privilegiadas, ou seja, de contínuas descentrações a partir de centrações prévias. Nesse processo, a medida em que o sujeito cognitivo se diferencia do outro é que ele pode integrá-lo na construção de seu pensamento ou de sua 
ação. Assim, considerar o ponto de vista do outro só pode acontecer quando as estruturas cognitivas são capazes de sustentar a reversibilidade do pensamento, não perdendo de vista toda a questão de afecção que este ato requer. Dizendo em outras palavras, em nosso caso, um emocionar que impulsiona o desejo de encontro com o outro, ou seja, aprendizagens amorosas.

\section{Metodologia de Projetos de Aprendizagem (PAs)}

Nossa investigação propôs por em análise uma experiência de convivência que, acoplada a ferramentas advindas das Tecnologias Digitais e a uma metodologia de Projetos de Aprendizagem, propiciasse exercícios de descentração intelectual e afetiva, que chamamos de aprendizagem amorosa e estariam na base da cooperação.

Escolhemos essa metodologia por acreditarmos ser um dispositivo capaz de modular a estrutura da convivência em direção a um exercício de legitimidade do outro, conservando a diferença.

Fagundes et all (1999) argumentam que os PAs apostam em uma concepção de aprendizagem distinta da presente na maioria das escolas tradicionais que são calcadas no ensino transmissivo. As autoras diferenciam Projetos de Aprendizagem de Projetos de Ensino, propondo uma metodologia específica para o trabalho com PAs.

Nos Projetos de Ensino o tema a ser estudado parte do professor e da coordenação pedagógica da escola; segue os conteúdos programáticos das matérias que constam no currículo escolar, oportunizando pouca interatividade, reciprocidade e cooperação. O professor é o agente do processo (o responsável por este) e o aluno deve ser receptivo à proposta de seus mestres. O modelo pedagógico presente é o da transmissão do conhecimento e o caminho explicativo é o da objetividade-sem-parênteses.

Nos PAs, o tema a ser estudado é levantado pelos alunos, de forma individual e em grupos, juntamente com os professores e a coordenação pedagógica. $\mathrm{Na}$ escolha dos assuntos leva-se em consideração a curiosidade e os desejos dos aprendizes. As regras e diretrizes são elaboradas pelo grupo de alunos e professores. Ao professor cabe o papel de problematizador, de desafiador. Alunos e professores são agentes no processo. A concepção presente é a da construção do conhecimento.

Na proposta de PAs, a organização dos domínios de ação entre professores e alunos tem como foco o convite à aprender. $\mathrm{O}$ aprendiz é desafiado a questionar e argumentar. Com isso, se perturba e necessita refletir para expressar suas dúvidas. A ele é solicitada a capacidade de formular e equacionar problemas, pois the é permitido propor questões que possuam significações. Esta significação emerge de sua história de vida, de seus interesses, de seus valores, de suas necessidades e de suas condições pessoais. Assim, existe a produção e a aceitação da posição do outro no domínio da aprendizagem, dentro de uma objetividade-entre-parênteses.

Os PAs trabalham com a autoria no sentido de referir à formulação de questões pelo autor do projeto, pelos sujeitos que aceitam essa modalidade de construir conhecimento. Fagundes et al afirmam:

[ . . ] é a partir das experiências prévias que o aprendiz vai interagir com o desconhecido, com novas situações, para se apropriar do conhecimento específico seja nas ciências, nas artes, na cultura tradicional ou na cultura em transformação. (1999, p. 16). 
Trata-se de uma proposta que configura os domínios de ação possibilitando determinadas relações entre aprendizes e professores e aprendizes-aprendizes que podem ser passíveis da emergência de um emocionar que considere a aceitação do outro, acolhendo o exercício da Aprendizagem Amorosa e possibilitando interações de cooperação (que se produzem em um domínio recursivo de ações de cooperação). Há cooperação entre os envolvidos, quando os objetivos são comuns e/ou diferentes, com troca de informações, materiais, idéias, sugestões; aceitação de diversidades de pensamentos nos modos de ser e de viver; realização e aceitação da crítica como um processo construtivo; respeito entre os envolvidos, tanto nas relações interpessoais como em relação ao conhecimento informal trazido pelos alunos à escola; consideração em relação aos conhecimentos construídos na comunidade e aos conteúdos formais oportunizados pela escola; responsabilidade nas escolhas.

Nos PAs a escolha de um tema de interesse individual e/ou grupal traz em si algo presente do emocionar de cada um dos participantes, ou seja, não é a à toa que se escolhe trabaIhar "hip hop", "pagode", "alimentação", "modelo", as escolhas estão ligadas às vivências. Nesse sentido, Piaget (2001) refere que não há trabalho sem necessidade; não há ato de inteligência sem pergunta, sem experimentar a sensação de uma lacuna, portanto, sem desequilíbrio, sem emoção.

\section{A experiência}

A experiência, que serviu de campo empírico desse trabalho, aconteceu em uma Escola Municipal de Ensino Fundamental de Porto Alegre. Foi caracterizada por uma pesquisa intervenção, considerando a atividade dos pesquisadores. Participaram dela duas turmas de B30, em torno de 30 alunos cada, com idades de 11 a 13 anos, duas professoras das turmas, duas estagiárias de psicologia e a pesquisadora. A experiência foi atualizada a cada encontro, tomando novos formatos, novos caminhos, abrindo diversas possibilidades.

O estudo teve a duração de 4 meses, com freqüência de duas vezes por semana, em cada uma das turmas, junto ao Laboratório de Informática (LI), utilizando-se na maioria das vezes um período de aula (em algumas ocasiões as interações ocorreram em dois períodos-aula). A presença de tecnologias digitais no desenvolvimento dos PAs permitiu que alunos realizassem suas pesquisas em grupo, construíssem páginas em html para apresentar seus resultados, também utilizassem o Teleduc (trata-se de um ambiente de ensino a distância pelo qual se pode realizar cursos através da Internet, está sendo desenvolvido conjuntamente pelo Núcleo de Informática Aplicada à Educação - Nied - e pelo Instituto de Computação - IC - da Universidade Estadual de Campinas. Possui vários espaços como fórum, diários de bordo, biblioteca, portfólio, local para postar atividades, e-mail, bate-papo, endereço eletrônico.) onde os alunos preencheram o perfil, fizeram diário de bordo, participaram de um fórum com a finalidade de relatarem a experiência vivida no ambiente informatizado. Seus trabalhos foram publicados no portifólio para que todos pudessem acessar e foi utilizado o bate-papo.

Os observadores - pesquisadora e estagiárias de psicologia - relataram os encontros em diários de campo que tornaram-se os guias principais da análise da experiência, além dos fóruns e bate-papo do Teleduc. Na pesquisa qualitativa, segundo Bogdan e Biklen (1994, p. 50 ), as notas de campo são de extrema importância. "As notas de campo são: o relato escrito daquilo que o investigador ouve, vê, experiência 
e pensa no decurso da recolha refletindo sobre os dados de um estudo qualitativo." O conteúdo das notas de campo são descritivos e reflexivos. A parte descritiva representa o esforço do investigador para registrar objetivamente os detalhes que ocorreram no campo incluindo as falas, gestos, imagens, descrevendo pessoas, ações e conversas observadas, reconstruções de diálogos, relatos de acontecimentos particulares, descrição de atividades. A parte reflexiva é onde apreende o ponto de vista do observador, são as reflexões do observador sobre os acontecimentos, suas idéias, preocupações, emoções geradas na experiência.

A partir da experiência na escola fizemos um recorte e vamos acompanhar as transformações na convivência de aceitação do outro como legítimo, ou seja, aprendizagens amorosas, a partir do estudo da participação de Adriano (nome fictício). Seguimos seu percurso, acompanhando-o nas interações no Laboratório de Informática, trazendo suas pesquisas, suas verbalizações-conversas formais e informais e suas escritas, flagrando as aprendizagens amorosas. Percorremos o caminho inferindo algumas emoções a partir da rede de conversações instaurada nesse espaço. Maturana (2002, p. 23) refere que observando as ações do outro "conheceremos suas emoções como fundamentos que constituem suas ações".

A escolha de Adriano se deve ao fato que houve consensualidade por parte do grupo de pesquisa, da professora e dele próprio na identificação de transformações em seu modo de ser e de se relacionar durante o percurso da experiência.

Nas primeiras observações em sala de aula, a professora chamava várias vezes a atenção de Adriano, pois no momento em que esta explicava algum conteúdo ou atividade o aluno perguntava sobre um assunto que não estava relacionado diretamente com o tema abordado. Demonstrava estar alheio e totalmente deslocado em relação a seus colegas que não queriam trabalhar com ele e vice-versa.

As primeiras relações observadas no grupo eram de isolamento, seguimos pelos diários de campo:

\section{$1^{\circ}$ encontro}

Adriano esta sozinho e ninguém quer sentar com ele, e ninguém quer que ele ajude. Os alunos mostram uma distância muito grande do aluno.

Adriano (visto como inquieto na primeira aula, no dia anterior) permanece concentrado em seu computador, mesmo quando este apresenta alguns problemas. Ninguém quis dividir o computador com ele e ele também não se dispôs a ensinar aos colegas. Dele provém um cheiro forte que invade a sala.

\section{3e encontro}

A professora intervém no sentido da necessidade do trabalho ser em grupo e faz com que Adriano aceite trabalhar com um colega, Guilherme. Essa primeira interação, de certa forma imposta por uma necessidade, com o passar do tempo, se transformará em uma parceria. Chamamos a atenção para a importância da intervenção apontando para o trabalho em grupo na rede de conversação gerada na experiência.

Adriano fica sem computador, e não quer sentar com ninguém. A professora esta na sala e explica para Adriano que ele terá que escolher alguém para trabalhar, que e desta vez ele não ficará sozinho. Todos se acomodam menos Adriano e Wellington diz 'que não estou afim' de fazer nada. A pesquisadora pede para que ele escolha alguém para compartilhar o computador, e ele conta a ela 
que está chateado com um amigo. Conta que não quer trabalhar com sua dupla porque o colega tocou borracha, após intervenção no sentido de mostrar que brigas acontecem mas eles podem se acertar a dupla volta a trabalhar.

Adriano senta-se ao lado de Guilherme e mexe o tempo todo com as mãos, parecendo fazer um esforço para controlar a vontade de tocar no teclado do computador. Guilherme ignora sua presença e, quando Adriano tenta digitar algo, ele empurra as mãos do colega.

No documento acima, observamos uma aproximação física de Adriano e Guilherme, entretanto, ainda não há interação entre eles. Não há encontro na emoção de ambos, Adriano é ignorado pelo colega. "Não é o encontro que define o que ocorre, mas a emoção que o constitui como ato" (MATURANA, 2002, p. 92). Pelas ações expostas, não existe aqui consideração da legitimidade da diferença de ambos.

\section{$4^{\circ}$ encontro}

O único aluno que esta sem computador é Adriano porque não quer sentar com ninguém. Com o término de um aluno de seu trabalho, Adriano tem a vez em um computador. Ele é orientado para que trabalhe sério pela bolsista $V$.

Durante o quinto encontro, inicia a interação de Adriano no computador de uma forma transformada, pois ele ativamente coloca-se objetivos a realizar. Seus colegas já haviam feito a página pessoal e estavam iniciando a pesquisa. Adriano pergunta se pode fazer a sua página, e lhe é permitido. Volta a perguntar se pode escrever a história de um mendigo. A pesquisadora afirma que ele pode escrever o que quiser, pois a página é dele. A aceitação da produção dele gera em Adriano um emocionar diferente do que ele estava acostumado, de não ser aceito em suas falas e suas produções, pois elas, muitas vezes, aconteciam em outro espaçotempo, no sentido de suas produções não pertencerem às solicitações da professora na sala de aula. Adriano conta que a mãe namorava um mendigo. Para Adriano, escrever sobre mendigo remete a sua própria história, onde nela própria Adriano se reinventa. Nessa circularidade de viver, ser, escrever, seu fora e seu dentro no mesmo movimento em que se encontram também se distanciam propiciando a construção/ invenção de sua identidade. Uma invenção de si a partir da colagem de experiências de vida é escrita em sua página pessoal. O espaço da experiência acolheu Adriano num movimento de amor. Talvez esse movimento proporcionou o espaço para as futuras aprendizagens amorosas em Adriano. Parece que no momento do acolhimento, há um nó diferente, transformado, na rede de conversações de Adriano em relação ao grupo gerando um emocionar amoroso. Logo, gerando também domínio de ações amorosas. O ambiente criado pode respeitar o ritmo e momento de Adriano. llustramos no seguinte documento:

Adriano chama a pesquisadora e pergunta se pode escrever uma história. Ela concorda e, com muita dificuldade e erros ortográficos escreve:

"era um maves um pobre omi queri pão ele andava narua do cetro e lê todos o dia ele midigava naru elecechamava Rafael ele tinha $31 "$ ".

A partir desse momento, seu acoplamento com o grupo começa a se transformar, pois solicita ajuda aos colegas e também procura interagir com eles. Nesse sentido, um grande esforço de aprendizagem amorosa é realizado por Adriano para manter a convivência e as relações. Princípio de um emocionar diferente da solidão inicial, Adriano procura ativamente conviver no grupo. Inicialmente as interações de seus colegas são no sentido de o desvalorizar, mas, 
aos poucos, transformam-se em aceitação. Chamamos a atenção que mesmo sendo interações de desvalorização não são de indiferença como em momentos anteriores onde os colegas nem tomavam conhecimento de que Adriano estava na sala de aula. Maturana (2002b, p. 45) refere que "a indiferença, em contraste com o amor e a agressão, é o domínio de condutas relacionais através das quais o outro não é visto como outro". Na indiferença, o outro não tem presença, pois o que sucede a ele está fora das preocupações do grupo. Adriano, mesmo nas desvalorizações, se mostra presente e, aos poucos, inicia o trabalho de parceria com colegas.

\section{6encontro}

Adriano passa um bom tempo circulando pela sala, até que encontra um computador que foi desocupado e vai diretamente ao Google procurar por fotos de mendigos. Os colegas que estão ao redor zombam de sua escolha. Bruno, que está no computador ao lado, sugere que Adriano procure sua própria foto na internet. Ele escreve e não encontra nada, então Bruno diz que o filme deve ter queimado na hora de tirar a foto, indicando que o colega era feio. Adriano resolve procurar a foto do colega Renan e um dos colegas diz: "tu só pode ser apaixonado por ele".

Bruno e Adriano pesquisam juntos sobre a Cohab, mas não encontram nada.

Adriano foi bastante persistente para acessar a internet, tentou muitas vezes e não desistiu fácil. Hoje interagiu um pouco com Bruno.

Aos poucos o ambiente na sala de informática vai se configurando de uma forma diferente da sala de aula, nessa última, cada aluno tem um lugar determinado e que não propicia escolher as parcerias. Entretanto, ainda são bastante rígidas as escolhas no sentido de al- guns alunos não quererem trabalhar com outros. $O$ acolhimento de idéias e colegas ainda se mostra difícil. Adriano convida Paulo para trabalhar com ele, podemos considerar uma aprendizagem amorosa de Adriano, pois inicialmente não queria trabalhar com ninguém, entretanto não acolhe as idéias de Paulo, sendo que nem o escuta. Foi necessária a intervenção de um adulto (P.) para ajudar as negociações entre Adriano e Paulo. Nesse momento, observamos como foram importantes as intervenções da equipe no sentido de propiciar aprendizagens amorosas. A partir das intervenções que geram domínios de ações de aceitação do outro, gera-se um emocionar baseado na cooperação e logo mais condutas de acolhimento ao outro. Continuamos na caminhada, agora com Adriano e seus colegas:

\section{$7^{\circ}$ encontro}

Paulo e Alessandra ficam sem computador. Juliane percebe e os convida para sentar com ela. Nenhum deles aceita. Logo Adriano convida Paulo para sentar-se com ele. Adriano pesquisa sobre as Ferraris e não presta atenção na sugestão de Paulo para pesquisar sobre ciclones.

Pela primeira vez Adriano (que exala um mal cheiro) aceita a participação de alguém. Atendidos pela estagiária $P$, ele negocia com Paulo o uso do teclado e concordam em que cada um escreva um pouco. No começo ele tenta interferir na digitação de Paulo mas depois espera sem problemas.

A fascinação pela informática é grande pelos alunos. No dia em que o trabalho é realizado no primeiro período de aula, os alunos chegam mais cedo e fazem fila na porta, uma colega refere que Marcos havia chegado às $7 \mathrm{~h}$ deste dia. Adriano impaciente sempre que vê as estagiárias na escola fica em volta perguntando que horas vai ser "o computador". Com toda essa emoção, no oitavo encontro, Adriano inicia cons- 
truindo sua página, se experimentando de outra forma, além do mendigo.

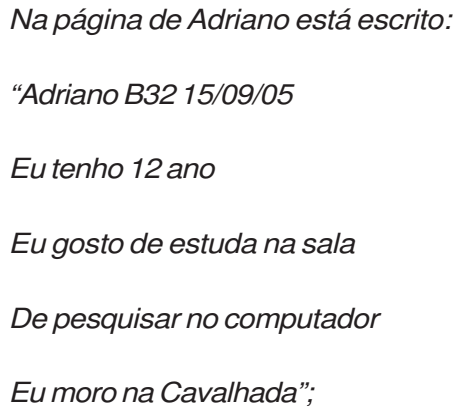

Adriano partilha com a turma o prazer de tirar fotos e olhá-las no computador para posteriormente colocar em sua página. Observamos a aprendizagem amorosa de Adriano e Guilherme quando ambos tiram uma foto em conjunto sorrindo e de braços abertos.

Adriano descobre como ver as fotos dos colegas e dá risadas de alegria, atraindo a atenção dos colegas.

Kelvin chega e Adriano o chama para mostrar a foto do colega e depois disso, ensina ao colega como fazê-lo. Adriano pede outra vez para tirar foto e dança pela sala quando a psicóloga o chama para isso. Depois de pousar para a primeira pede que se tire outra e, desta vez, tira uma linda foto com Guilherme.

A transformação de Adriano é relatada também pela professora Jaqueline, pois o aluno começa a ser mais ativo em outros espaços da escola. Percebemos como é importante a intervenção de um adulto no sentido de abrir espaços para que Adriano possa exercer sua atividade. No dia da apresentação de Mário Pirata, ator que vem à escola, Adriano tem vontade de pedir um autógrafo e só realiza seu desejo com a intervenção da estagiária. Consideramos estas intervenções como propiciadoras de aprendizagens amorosas. Partilhamos do emocionar de
Adriano gerado na rede de conversações nos domínios de ações de alegria nos próximos documentos do $10^{\circ}$ encontro.

Adriano está eufórico e se aproxima dizendo que vai pedir um autógrafo de Mario Pirata. O aluno é incentivado para que peça o autógrafo, e ele vai. Chega ao fim a apresentação os alunos voltam para a sala de aula.

Quando ele anuncia que vai embora, Adriano diz:

“- fica mais 5 horas". Quando poeta pergunta se as crianças querem ouvir poemas de amor ou de terror a grande maioria responde que gostaria de escutar poemas de terror. Adriano pede uma caneta emprestada e pega seu caderno para conseguir um autógrafo. Vai para a parte da frente do local, onde está sendo realizada a apresentação e professora Jaqueline conversa com ele calmamente, pedindo que espere o final da mesma. Logo que encerra as crianças lamentam e saem bastante contentes com o programa. Adriano consegue seu autógrafo e volta contente para a sala de aula.

Depoimentos de Adriano:

\section{Entrevista Adriano}

Pergunto o que está achando das aulas no laboratório e ele responde que está gostando, que o que mais gosta são os textos que ele fez. Seus temas escolhidos para pesquisar foram o futebol e mendigos. Pergunto o motivo de haver escolhido o segundo tema e ele responde que foi por causa do ex-namorado da mãe. Conta, então, que ele virou mendigo depois de se separar da sua mãe e que descobriu esse fato em um dia em que passava de ônibus pela Cavalhada e viu o rapaz deitado no chão. Conta que ele era legal e que namorou bastante tempo com a mãe, gostava muito dele. Pergunto sobre sua família e ele conta que atualmente mora com os pais e um irmão. Pergunto sobre 
Dai, sua irmã da B31, e ele diz que ela mora com uma tia e "com uma irmã dela". Pergunto se a irmã de Dai é sua irmã também e ele responde que sim, por parte de mãe. Desvia o assunto dizendo que gostou muito das fotos e pergunta se não é possível imprimi-las, em tê-las em um papel para poder mostrar à sua mãe. Digo a ele que podemos conversar com a professora Luciane sobre o assunto. Pergunto se a mãe dele é legal e ele diz que gosta de morar com ela. Pergunto como está com a turma e ele contesta que está tudo bem. Pergunto se está melhor, igual ou pior que no início do ano e ele diz que "melhorou ou está tudo igual". Disse que uns seis colegas estão mais legais, entre eles Giselle, Karine, Brenda e outros. Pergunto sobre algum dos guris e ele diz que GuiIherme.

A professora relata que é a primeira vez que Adriano se integra no grupo para participar de algum campeonato. Pertencer a um grupo, ter um lugar nele, ser valorizado e se valorizar são indicadores de aprendizagens amorosas. Adriano, na mesma maneira que foi acolhido pela equipe de pesquisa, começou a acolher colegas. Num movimento recursivo, circular, que envolve descentração e condutas de aceitação do outro, observou-se as aprendizagens amorosas de Adriano.

O prazer da convivência na experiência propicia condutas ativas nesse espaço. Acompanhamos no documento do $11^{\circ}$ encontro.

Os alunos da B32 entram correndo, Adriano me chama para mostrar as folhas que trouxe e diz: 'Oh sôra eu truxe a folhas pra imprimi as fotos'. Os alunos vão entrando e se acomodando.

Adriano o está olhando figuras de Ronaldinho Gaúcho e Rafael vai até o computador do colega para ver também. Carina entra no Google e continua sua pesquisa sobre planetas enquanto Rafael vê as figuras de futebol. A pesquisadora explica que os alunos devem colocar textos, e figuras se quiserem também.

Aos poucos, a nova posição de Adriano na turma vai se confirmando, tanto no LI como em outros espaços da escola, passa a ensinar os colegas, ajudando em suas dificuldades. Participa ativamente da dinâmica do grupo, fazendo parte dos momentos de acolhimento deste como também de momentos de rixas entre eles, próprio das relações dessa idade.

No $17^{\circ}$ encontro a proposta foi dos alunos apresentarem os trabalhos uns aos outros e Adriano também apresenta.

Adriano pede muitas vezes para apresentar. Quando anunciam sua vez ele levanta sorrindo e anda com um caminhar malandro. Monitora V. decide que será melhor Guilherme apresentar primeiro e ele volta para seu lugar entristecido.

Guilherme diz: "comecei sozinho, mas na metade veio o Paulo. Ele estava sozinho e eu deixei ele fazer comigo".

Adriano e Paulo: Ele vai para outro computador não está sendo usado e abre seu arquivo antes mesmo que a monitora o fizesse. Os colegas olham o texto e riem dos erros ortográficos até que a professora os chama a atenção. Ele lê em voz bem baixa. Paulo reluta em apresentar sua parte. Sugestões: arrumar os erros de português, incluir mais fotos. Kelvin diz para Adriano anotar as sugestões para poder lembrar.

\section{0 encontro - o bate-papo}

Os participantes do chat ficaram em duplas e até mesmo trios. Pedimos que colocassem como "nick" o nome de todos os participantes em cada máquina para melhor identificação. Foi muito divertido ver eles perceberem que o que escreviam, 
automaticamente iria surgir na tela dos outros colegas. Alguns iam na tela do colega pra conferir se já tinha chegado a mensagem. Ficaram fascinados. É claro que ofensas ocorreram por parte daqueles que não sabiam que poderíamos identificá-los, mas a experiência foi válida porque muitos queriam realmente participar de forma produtiva.

Adriano participou do chat juntamente com o GuiIherme. Adriano pedia ao Guilherme que escrevesse algumas mensagens pra Carina, porque se ele escrevesse, ela "não ia entender por causa dos erros". Praticamente todas as mensagens que o Guilherme escreveu foram a pedido do colega Adriano. O Rafael também escreveu algumas mensagens para a Carina a pedido do Adriano. Um ponto interessante aqui é que o Adriano assinava ao final da mensagem.

Nesse espaço, observamos atitudes que revelam aprendizagens amorosas do grupo. $\mathrm{O}$ emocionar gerado pela atividade de conversar pelo computador com os colegas e professora proporcionou um ambiente descontraído. Pudemos observar como o fluir na mudança emocional modifica as ações como nos aponta Maturana (2004). Os erros não são criticados, mas em uma atitude de cooperação corrigidos entre os colegas, por perceberem a importância de serem entendidos através da escrita. Mesmo que um só utilizasse o teclado, os outros participantes no mesmo computador ajudavam na elaboração da mensagem.

\section{Concluindo}

Acompanhando esse caso, podemos observar as coordenações de coordenações consensuais de ações transformando-se a partir do emocionar presente no grupo. Na rede de conversações do grupo na qual participaram/ enatuaram os observadores com seus registros, pode-se observar as transformações na convi- vência de aceitação do outro como legítimo, ou seja, as aprendizagens amorosas.

Caminhando com Adriano na experiência, observamos as transformações em sua conduta em relação a ele próprio e ao grupo, assim como do grupo em relação a ele. Seguimos os movimentos dessas transformações e percebemos a importância das intervenções de reconhecimento para a inclusão de Adriano na rede de conversações da turma. Um momento importante foi a aceitação de sua produção no instante que ele desejou, a construção de uma história sobre o mendigo na qual reinventa sua própria história. A partir daí seu acoplamento com o grupo se transforma e começa a solicitar ajuda dos colegas. Na circularidade do entrelaçamento do linguajar com o emocionar, Adriano começa a ter um lugar no grupo, sai da indiferença, mesmo que esse lugar seja de desvalorização. Aos poucos, a partir de suas ações no sentido de incluirse no grupo, e com as intervenções baseadas na cooperação do grupo de pesquisa, Adriano passa a fazer parte da rede de conversações da turma em uma posição diferente, de um aluno como todos os outros nessa fase de desenvolvimento criticado, elogiado, reconhecido. Concordamos com Maturana (2002, p. 31) quando refere que "sem aceitação e respeito por si mesmo não se pode aceitar e respeitar o outro, e sem aceitar e respeitar o outro como legítimo outro na convivência, não há fenômeno social", continuando afirma que uma criança que não se aceita e que não se respeita não tem espaço de reflexão, porque está na contínua negação de si mesma e na busca do que não é nem pode ser.

O espaço no LI aliado a uma proposta construtivista (PAs) propiciou um emocionar diferente do usual da sala de aula. Fez parte disso os recursos da informática como a Internet, o fórum, o bate-papo, o perfil no Teleduc, e as intervenções dos participantes da equipe de pes- 
quisa no sentido do trabalho em grupo gerando momentos de cooperação propiciando descentrações nos participantes do grupo.

Dentro desse movimento dinâmico, relatado nos documentos descritos, podemos acompanhar algumas aprendizagens amorosas do grupo e de Adriano.

Finalizando, ilustramos com umas das últimas atividades propostas na experiência realizada por Adriano que foi o preenchimento do perfil no Teleduc. Nessa descrição que ele faz de si, podemos observar suas transformações em relação a ele próprio, colocando suas preferências e desejos como em relação a sua posição no grupo.

Perfil teleduc
Adriano
Email: leocadiab32
Função: aluno.
Meu nome é Adriano touna turma b32 giuto de
joga fatebol eu sou bunito gosto da carina vou
leva a carina para o cinema-

\section{REFERÊNCIAS}

ALMEIDA, Fernando José de; FONSECA JÚNIOR, Fernando Moraes. Projetos e ambientes inovadores. Secretaria de Educação a Distância. Brasília: MEC, 2000.

AZEVEDO, Ana Maria Ponzio de et al. Informática na Educação: teoria \& prática, Porto Alegre, v. 7, n. 1, p. 59-71, jan./jun. 2004.

BASSO, Marcus Vinicius de Azevedo et al. Educação tecnológica e/na educação matemática aplicações da matemática elementar na sala de aula ou "focinho de porco não é tomada". Informática na Educação: teoria \& prática, Porto Alegre, v. 2, n. 2, p. 23-37, 1999.

BOFF, Elisa; GIRAFFA, Lucia Maria Martins. Ambiente para construção cooperativa de histórias em quadrinhos. Revista Brasileira de Informática na Educação, Porto Alegre. v. 10, n. 1, p. 9-19, abr. 2002. BOGDAM, Robert; BIKLEN, Sari Knopp. Investigação qualitativa em educação. Portugal: Porto Ed., 1994.

CRISÓSTOMO, Vicente Lima et al. Tecnologia da informação no ensino de contabilidade.

Revista Brasileira de Informática na Educação, Porto Alegre, v. 10, n. 1, p. 45-52, abr. 2002.

EICHLER, Marcelo. Uma abordagem construtivista para a aprendizagem de ciências com o uso do computador. Informática na Educação: teoria \& prática, Porto Alegre, v. 2, n. 2, p. 55-64, 1999.

ESTRÁZULAS, Mônica. Interação e cooperação em listas de discussão. Informática na Educação: teoria \& prática, Porto Alegre, v. 2, n. 2, p. 81-86, 1999.

FAGUNDES, Lea; SATO, Luciane; LAURINO-MAÇADA, Débora. Aprendizes do futuro: as inovações começaram! Brasília: SEED; MEC; PROINFO, 1999. (Informática para a mudança na educação).

FUKS, Hugo et al. O modelo de colaboração 3C no ambiente AulaNet. Informática na Educação: teoria \& prática, Porto Alegre, v. 7, n. 1, p. 25-48, jan.jun. 2004. 
FUKS, Hugo; GEROSA, Marco Aurélio; LUCENA, Carlos José Pereira de. Usando a categorização e estruturação de mensagens textuais em cursos pelo ambiente AulaNet. Revista Brasileira de Informática na Educação, Porto Alegre, v. 10, n. 1, p. 31-44, abr. 2002.

GLADCHEFF, Ana Paula. Um instrumento de avaliação da qualidade para software educacional de matemática. Revista Brasileira de Informática na Educação. Porto Alegre, v. 10, n. 1, p. 69-70, abr. 2002.

A sociedade do conhecimento e a educação a distância. In: CAPISANI, Dulcimara (Org.).

Educação e arte no mundo digital. Campo Grande, MS: UFMS, 2000. p. 21-32.

; ZANIOL, Elisângela. Navegando pela cooperativa: percepção e expectativas dos usuários. Informática na Educação: teoria \& prática, Porto Alegre, v. 7, n. 1, p. 73-85, jan./jun. 2004.

MATURANA, Humberto. Uma nova concepção de aprendizagem. Dois pontos, v. 2, n. 15, 1993.

El sentido de lo humano. Chile: Pedagogicas Chilenas, 1992.

A ontologia da realidade. Belo Horizonte: UFMG, 1999.

Formação humana e capacitação. Petrópolis: Vozes, 2001a.

Cognição, ciência e vida cotidiana. Belo Horizonte: UFMG, 2001b.

Emoções e linguagem na educação e na política. Belo Horizonte: UFMG, 2002.

; VARELA, Francisco. A árvore do conhecimento. São Paulo : Palas Athena, 2002.

; ZÖLLER, Gerda V. Amar e brincar: fundamentos esquecidos do humano. São Paulo: Palas

Athena, 2004.

MONTAGERO, Jacques; MAURICE-NAVILLE, Danielle. Piaget ou a inteligência em evolução. Porto Alegre: Artmed, 1998.

NEVADO, Rosane Aragon et al. Um recorte no estado da arte: O que está sendo produzido? O que está faltando segundo nosso sub-paradigma? Revista Brasileira de Informática na Educação, Porto Alegre, v. 10, n. 1, p. 61-68, abr. 2002.

; MAGDALENA, Beatriz Corso; COSTA, Iris Elisabeth Tempel. Formação de professores multiplicadores: nte2@projetos.cooperativos.ufrgs.br. Informática na Educação: teoria \& prática, Porto Alegre, v. 2, n. 2, p 127-139, 1999.

NITZKE, Júlio; FAGUNDES, Lea. Uma tentativa de utilização da informática para a introdução do Costrutivismo na agronomia. Informática na Educação: teoria \& prática, Porto Alegre, v. 2, n. 2, p. 1121, 1999.

PAULA, Érico Lopes Pinheiro de. Fundamentos biológicos da mente e do conhecimento e suas implicações nas ciências humanas. Trabalho de Conclusão de Curso em Ciências Sociais, Faculdade de Ciências e Letras da Universidade Júlio de Mesquita Filho, Araraquara, 2001. Orientador: Prof. Dr. Sérgio Gertel.

PIAGET, J. A formação do símbolo na criança: imitação, jogo e sonho, imagem e representação. Rio de Janeiro: Zahar, 1971.

Para onde vai a educação? Rio de Janeiro: J. Olympio, 1973

A linguagem e o pensamento da criança. São Paulo: M. Fontes, 1973a.

Estudos sociológicos. Rio de Janeiro: Forense, 1973b. 
A equilibração das estruturas cognitivas : problema central do desenvolvimento. Rio de Janeiro: Zahar, 1977.

Inteligencia y afectividad. Buenos Aires: Aique, 2001.

PIMENTEL, Mariano Gomes; SAMPAIO, Fábio Ferrentini. Comunicografia: uma metodologia para análise de processos de interação que se desenvolvem nas ferramentas de comunicação textual da Internet utilizadas no contexto da educação a distância. Revista Brasileira de Informática na Educação, Porto Alegre, v. 10, n. 1, p. 53-59, abr. 2002.

RAMAL, Andrea Cecilia. Educação na cibercultura: hipertextualidade, leitura, escrita e aprendizagem. Porto Alegre: Artmed, 2002.

RÜTHSCHILLING, Evelise Anicet. Avaliação de software educacional "curso interativo de design de superfície”. Informática na Educação: teoria \& prática, Porto Alegre, v. 2 n. 2, p. 109-115, 1999.

SENO, Wesley Peron; VIEIRA, Marina Teresa Pires. Educação sem distâncias: DE-MAW: um ambiente de educação a distância. Revista Brasileira de Informática na Educação. Porto Alegre, v. 10, n. 1, p. 21-29, abr. 2002.

TEIXEIRA PRIMO, Alex Fernando; CASSOL, Márcio Borges Fortes. Explorando o conceito de interatividade: definições e taxonomias. Informática na Educação: teoria \& prática, Porto Alegre, v. 2 n. 2, p. 65-80, 1999.

TEIXEIRA, Alex Niche. Análise de dados qualitativos com NUD*IST. Instituto de Filosofia e Ciências Humanas, 2005.

VALENTINI, Carla et al. CAVI: Criando Ambientes Virtuais Interativos. Informática na Educação: teoria \& prática. Porto Alegre, v. 2, n. 2, p. 87-97, 1999.

; FAGUNDES, Lea. Fundamentação da psicologia em aplicações da informática na educação. Informática na Educação: teoria \& prática, Porto Alegre, v. 2, n. 2, p. 117-125, 1999.

Recebido em fevereiro de 2007

Aceito para publicação em maio de 2007

\section{Luciane Magalhães Corte Real}

Mestre em Psicologia do Desenvolvimento pela UFRGS, docente adjunta do Departamento de Estudos Básicos da Faculdade de Educação - UFRGS

Cleci Maraschin

Doutora em Educação pela UFRGS e docente do Programa de Pós-Graduação em Informática na Educação da UFRGS.

Margarete Axt

Doutora em Lingüística Aplicada - PUCRS, docente na Faculdade de Educação UFRGS e nos programas de pós-graduação em Educação e em Informática na Educação, e coordenadora do Laboratório de Estudos em Linguagem, Interação e Cognição. 
teoria \& prática Porto Alegre, v.10, n.1, jan./jun. 2007. ISSN 1516-084X 